\title{
Elemen Citra Kawasan Ampel Surabaya Dalam Perspektif Historik dan Arkeologi
}

\author{
Ferril Pamungkas Maramba Putra, Karina Pradinie Tucunan \\ Departemen Perencanaan Wilayah dan Kota, Fakultas Teknik Sipil, Perencanaan, dan Kebumian \\ Institut Teknologi Sepuluh Nopember, Surabaya, 6011 \\ e-mail:kp.tucunan@gmail.com
}

\begin{abstract}
Abstrak-Kota Surabaya memiliki kawasan cagar budaya yang memiliki nilai sejarah di daerah Ampel yang bernilai sejarah Islam. Namun, situs tersebut mengandung fitur, struktur, serta artefak yang tidak sesuai dengan karakteristik negara magrib. Penelitian bertujuan menganalisa pengaruh akulturasi dalam aspek desain perkotaan situs Ampel dan implikasi pertumbuhan masa depan daerah tersebut. Dipersembahkan oleh pendekatan etnologi, penelitian ini menemukan bahwa selain Islam, ada beberapa pengaruh Hindu dan juga Jawa (budaya lokal) yang membentuk situs warisan Islam ini.

Pengaruh Islam ditemukan dalam aspek berikut: (1) path, komponen pola sirkulasi grid-linear yang terdiri dari jalan utama (syari), jalan kecil (fina), dan pola buntu (cul-de-sac); (2) pada area publik, fungsi sebagai komponen simpul yang dapat diakses oleh siapa saja. Itu terletak di sekitar area ekspansi Masjid Ampel; (3) ujungnya, komponen ini adalah pasar lokal (suq), yang juga ada di banyak negara magrib; (4) distrik, komponen ini terdiri dari tiga bagian, yang merupakan distrik pemukiman, distrik ibadah, dan distrik suqs berorientasi ke Masjid Ampel; (5) terakhir, komponen Landmark adalah Masjid Ampel sebagai pusat wilayah.

Sedangkan, aspek desain perkotaan mengadopsi pengaruh Islam, ornamen, warna, dan simbol mewakili pengaruh Hindu sebagai warisan Kerajaan Majapahit. Pertama, pada komponen tepi, adalah warisan Kerajaan Majapahit dalam bentuk gerbang (paduraksa) sebagai daerah transisi menuju ruang suci di masjid, konsep ini hampir tidak digunakan pada desain perkotaan Islam. Kedua, penggunaan ornamen Kerajaan Majapahit Surya Wilwatika yang berarti kekuatan dan kemenangan, tanaman memanjang yang berarti kesuburan, kuncup bunga yang berarti banyak biji, delapan di mahkota bunga.

Pengaruh Jawa ditemukan di Masjid Ampel (tengara). Ini adalah bentuk atap bertingkat tiga konsep kosmologis. Konsep ini mencoba menginternalisasi tiga tindakan (rasio-akal-hati), maka akan menyatukan untuk membentuk atap yang disebut atap Tajug. Kedua, pengaruh Jawa juga ditemukan di ujung atap Masjid Ampel sebagai mustika (mahkota), ciri khas budaya Jawa, dan mendefinisikan otoritas tertinggi untuk Tuhan.
\end{abstract}

Kata Kunci-Ampel, Kawasan Islam, Urban Heritage

\section{PENDAHULUAN}

$\mathrm{K}$ ota Surabaya adalah salah satu kota yang mempunyai banyak cagar budaya bersejarah di dalamnya, Islamic Heritage adalah salah satu dari beberapa cagar budaya tersebut, Islamic Heritage berada di daerah Ampel Surabaya yang merupakan satu di antara beberapa tempat bersejarah dalam Islam. Pusat cagar budaya keislaman tertua di Surabaya adalah Masjid Sunan Ampel yang merupakan pusat penyebaran agama Islam di Surabaya. Selain masjid Sunan Ampel, di sana juga terdapat makam para Wali yang menyebarluaskan agama Islam. Hal ini menjadikan Ampel sebagai kawasan wisata religi, pusat pendidikan keagamaan, yaitu Islam, tempat ibadah, serta terdapat pemukiman warga sekitar [1]. Menjadi pusat religi dan budaya membuat kawasan Ampel memiliki dinamika yang tinggi dan perubahanperubahan kenampakan kota mulai terlihat tidak teratur (Bappeko Kota Surabaya). Akulturasi dalam penelitian Tucunan, et all (2019) terjadi secara masif pada kawasan kawasan heritage Islam dan menyebabkan stakeholder kehilangan makna pada kawasan yang ada. Simbol-simbol yang ada di kawasan cagar budaya Islam seringkali tidak menjadi sebuah pusat perhatian disebabkan kaburnya elemen pembentuk kawasan yang ada [2].

Citra sebuah kawasan berkaitan erat dengan identitas dari beberapa elemen. Hal ini sesuai dengan yang telah jelaskan oleh Teori Kevin Lynch bahwa dalam suatu kawasan yang memiliki karakter dan ciri khas akan menciptakan sebuah jati diri dan menjadi sebuah pembeda dengan kawasan lainnya. Kesan fisik merupakan salah satu poin yang dapat memberikan ciri khas sebuah kawasan. Keadaan suatu kawasan yang terlihat akan membuat kesan baik atau tidaknya suatu daerah. Kesan tersebut menjadikan suatu daerah atau kawasan dikenali. Hal itu juga dapat menciptakan gambaran yang akan menjadi identitas suatu kawasan. Identitas tersebut yang dijadikan sebagai tolok ukur lingkungan dalam suatu wilayah. Kualitas dan cara pandang orang dapat mempengaruhi nilai wilayah tersebut [3]. Elemen pembentuk citra sebuah kawasan yaitu berupa path, edges, district, nodes, dan landmark. Jika kawasan tersebut mampu memenuhi 5 elemen citra tersebut, maka citra sebuah kawasan akan terbentuk seiring dengan berjalannya waktu [4].

Citra kota adalah gambaran sebuah kota yang dapat dilihat oleh warga sekitar maupun masyarakat lainnya dalam ingatannya [5]. Keterkaitan lokasi objek satu dengan yang lain dalam sebuah kawasan dapat mempengaruhi citra kawasan tersebut. Kuatnya keterkaitan suatu objek dalam satu lingkungan dapat memicu manusia untuk lebih mudah mengenali di mana objek tersebut berada. Wajah atau tampilan fisik suatu kota sangat penting untuk menarik keterikatan antar masyarakat dan lingkungan yang merupakan hal utama citra suatu kota. wajah suatu kota dapat menciptakan image dalam ingatan masyarakat yang merupakan pengamat. Kualitas tampilan fisik akan membentuk imageability yang dapat 
membentuk legibility. Imageability adalah kekuatan yang dapat menarik kesan bagi seseorang (pada sebuah tempat). Sedangkan legibility adalah kemudahan suatu kota untuk diingat. Teori Lynch ini sering dijadikan ukuran dalam masyarakat terhadap suatu lingkungan kota.

Citra kota yang baik sangatlah penting. Hal ini dapat berdampak pada kemudahan pengguna jalan di sebuah kota dalam mengingat dan tidak mudah tersesat sehingga membuat nyaman warga sekitar, serta menciptakan keselarasan antar kota. menurut Kevin Lynch dalam penelitiannya, citra kota sangat berkaitan dengan tiga komponen, yaitu identitas, struktur, dan makna.

Selanjutnya, dikatakan oleh Lynch, bahwa citra atau gambaran mental orang terhadap suatu tempat berkaitan dengan 3 komponen, yaitu sebagai berikut :

\section{Identitas}

Objek satu dengan yang lain dapat dibedakan. Dengan artian masyarakat dapat melihat gambaran suatu kota dan dapat dengan mudah mengingat objek yang ada.

\section{Struktur}

Acuan kaitan antar objek dengan pengamat dan objek dengan objek lainnya pada suatu tempat. Yaitu masyarakat dapat memahami pola suatu kota dengan melihat objek dengan objek lainnya di kota tersebut, melihat hubungan antara warga dengan objek yang ada,

\section{Makna} dan juga hal lainnya yang dapat dilihat.

Suatu makna yang diberikan oleh objek atau lingkungan terhadap pengamat. Yaitu masyarakat dapat merasakan kawasan perkotaan dengan memahami arti suatu objek, subjek dan terdapat perasaan yang tenngah dialaami.

Lynch meringkas terdapat lima kategori elemen yang diperlukan untuk menggambaran pemahaman dari beberapa tempat, yaitu landmark, nodes, edges, dan district.

\section{Path (jalur)}

Path adalah lintasan utama yang dilalui oleh para manusia yang dapat menciptakan rasa dalam benak mereka saat melintas kota. Path merupakan salah saatu wajah utama kota yang diperlukan untuk membentuk citra kota tersebut. Hampir semua orang dapat melalui jalur ini dengan mudah. Hal ini dikarenakan Path adalah komponen dalam sebuah kota yang juga mudah diingat atau dikenali. Hal tersebut bisa berbentuk jalan, trotoar, view dan lainnya. Hal yang paling mudah dikenali dan diingat oleh manusia dari path adalah jalan, karena mereka mencatat kondisi dalam ingatan mereka saat melalui jalan tersebut. Path juga menjadi penyusun dan penghubung elemen citra kawasan lainnya. Path akan terasa lebih baik jika pengamat memiliki rencana mengenai tempat tujuan (menuju stasiun, alun-alun, dan tugu), memiliki pola bentuk yang kuat (fasad dan pohon), dan juga memiliki rute yang teraba.

\section{Edge (batas)}

Edge adalah komponen yang terdapat di antara dua kawasan dan dapat dikenali oleh orang. Edge memiliki fungsi sebagai batas area di suatu kawasan atau wilayah yang menjadi identitas wilayah tersebut. Batas tersebut dapat dijumpai dengan wujud pantai, dinding, deretan bangunan, atau jajaran pohon dan lainnya. Edge juga dapat berbentuk pagar, tembok, atau sungai sebagai pembatas dua kawasan. Contoh batas ini adalah dinding kraton yang membatasi kawasan dalam keraton dan luar kraton. Dinding kraton ini dapat disebut dengan edge.

\section{District (kawasan)}

District adalah kawasan kota dalam skala dua dimensi memiliki ciri (bentuk, pola, dan wujudnya) dan juga khas di batasnya, saat orang "masuk" dan "keluar" dari suatu kawasan. District dapat dilihat dari pola atau bentuk bangunan dan fungsinya yang memiliki kemiripan atau homogen.

\section{Node (simpul)}

Node adalah titik pertemuan beberapa garis dalam suatu daerah yang strategis. Tempat bertemunya orang-orang dalam kapasitas banyak dan mereka melakukan aktivitas merupakaan ciri utama node. Node bisa berbentuk persimpangan lalu lintas, stasiun, lapangan, dan juga jembatan. Node dalam ukuran besar dapat berupa taman, plaza, square, ataupun pasar. Node akan menjadi lebih baik jika mempunyai pola yang jelas, mudah diingat, serta mempunyai gambaran yang berbeda dari lingkungan sekitarnya melalui fungsi dan bentuknya.

\section{Landmark (tetengger)}

Landmark adalah acuan yang memiliki bentuk menonjol sebagai parameter yang memiliki sifat eksternal untuk para pengamat. Hal ini dikarenakan landmark dapat dilihat dari luar tempatnya. Sebagai contoh Landmark kota yaitu bangunan tinggi, penanda jalan, toko, ataupun gunung/bukit. Landmark merupakan komponen penting dari bentuk suatu kawasan karena dapat digunakan untuk mengenalkan kawasan tersebut dan dapat membantu orang dengan mudah mengenali suatu tempat. Landmark memilikii ciri khas karena jelas dan unik berbeda dari sekitarnya, mudah diingat, serta familiar.

\section{A. Pendekatan Islam dalam Perancangan}

Sejarah berkembangnya sebuah kawasan biasanya memiliki kesinambungan dengan Locallity dan sense of place pada lingkungan tersebut. Sejarah sebuah wilayah dapat membuat wajah suatu kota yang sedikit demi sedikit akan membaur dengan keadaan, hal itu yang membuat kawasan tersebut berkarakter (mempunyai sense).

Sebuah kota selalu memiliki keistimewaan yang khas, hal ini dapat dilihat dari tata letak dan juga rancangannya. Kota yang memiliki lingkungan sebagi pusat penyebaran agama Islam juga demikian. Bentuk dan rancangan yang sesuai dengan ajaran agama sangat diperhatikan dalaam membangun sebuah kota. Pola bentuk suatu kota yang merupakan lingkungan Islam sangat mementingkan privasi. [6]. Privasi yang dibentuk dapat dilihat dari bangunan publik yang dipisah dengan rumah-rumah pribadi mereka. Umat muslim sangat memperhatikan proporsi yang ada di ranah publik dan privat. Rumah-rumah pribadi dibangun secara tertutup dan memiliki batas yang jelas dengan dunia luar. Bangunan rumah privat sering didapati halaman yang mengelilinginya sebagai symbol privasi[6]. 
Wajah sebuah kota yang bernuansa Islam sering terlihat adanya bangunan yang rapat dan saling berhadapan satu sama lain, oleh karena itu terbentuklah beberapa gang dan jalaan yang lebih sempit dari jalan utama dan juga cul-de-sac [6]. Masjid jamik menjadi salah satu fasilitas umum di pusat kota yang bernuansa Islami. Di samping itu juga terdapat madrasah, pusat perbelanjaan atau pasar dan akan dijumpai para pedagang di jalan utamanya. Banyaknya pemukiman muslim yang mengisi jalanan kota dan daerah pemukiman didapati di pusat kota. Kota-kota Islam sangat kental denga kehidupan yang religius dan berkaitan erat dengan Tuhan, serta di lingkungannya dengan mudah dijumpai tempat-tempat peribadatan yang sudah tersebar sebagai bentuk fasilitas sosial [6]. Indonesia memiliki banyak masjid jamik yang telah tersebar dan menjadi pusat kegiatan umat muslim, di lingkungan masjid juga terdapat ruang terbuka dan pasar yang bisa digunakn oleh masyarakat sekitar. Ruang terbuka difungsikan sebagai perluasan yang digunakan untuk perayaan hari besar, misalnya shalat hari raya. Hal ini merupakan unsur utama di dalam pemukiman yang didominasi oleh masyarakaat Islam. Masjid juga digunakan untuk beberapa kegiatan keagamaan dan kemasyarakatan [6].

Tetuko (2001) berpendapat bahwa persebaran kota-kota Islam memiliki ciri sebagai berikut[6] :

1. Ada 4 (empat) persebaran di lingkungan pemukiman tersebut antara lain: grid, radial, hierarki, dan looping.

2. Bentuk jalinan jalan dibagi menjadi 2 (dua), yaitu: jalan utama yang sempit (public) dan jalan-jalan cul-de-sac (semi private). Kelas dan fungsi menjadi pemisah antara bangunan yang bersifat umum dan pribadi.

3. Ada 3 (tiga) kelas jalan yang telah dibagi yaitu: jalan utama (shari), jalan kecil/lorong (fina) dan jalan culde-sac (darb).

4. Jalan utama dan bangunan rumah saling berhadapan menjadi wajah utama bagi kota Islam.

\section{B. Pendekatan Jawa dalam Perancangan}

Holy city merupakan salah satu kota yang terbentuk pada awal terciptanya kerajaan Mataram. Salah satu yang menjadi patokan penataan kota adalah agama. Hal ini disebut sebagai konsep atau paham kosmologi. Dalam paham kosmologi, titik inti suatu kerajaan dan tanda kekuasaan raja yang berkuasa adalah keraton. Lain halnya dengan adanya Masjid Agung sebagai tanda bahwa raja adalah wakil Tuhan (kalifatullah). Pasar juga dijadikan sebagai tanda kemakmuran. Berbagai kegiatan koleksi dan distribusi produk hasil bumi maupun jasa di lakukan di dalam pasar. Kegiatan yang dilakukan melibatkan banyak orang dengan berbagai kepentingan,untuk itu suasana yang kondusif sangat diperlukan agar kegiatan yang dilakukan dapat terus berlangsung. Dalam hal ini proses administrasi dan pembagian tugas harus terkontrol sehingga pasar akan berjalan lancar [7].

Gambaran sebuah kota ideal ditunjukkan di awal terbentuknya kota Kerajaan Mataram. Geografis dan budaya yang membatasi sebuah kota dengan adanya penguasa. Raja dari dinasti Kerajaan Mataram yaitu Sultan Agung mulai mewujudkan kota ideal pada masanya. Kuthogoro dipilih sebagai permukiman penguasa, Negaragung sebagai tanah lungguh para pangeran dan petinggi, Monconegoro sebagai wilayah para bupati, dan lapis paling luar terdapat Pasisiran [7].

\section{Pendekatan Hindu dalam Perancangan}

Konsep psikokosmis dalam Hindu disebut atman atau jiwa setiap entitas bisa juga disebut kosmos yang setiap entitas dasarnya "organisme hidup". Dalam permukiman tradisional Bali yaitu desa adat, konsep psikokosmis terwujud dalam kahyangan desa berisi pura-pura tri kahyangan dan lainnya yang berada di suatu desa. Ritual dilakukan dengan interaksi antara tiga dunia atau tri loka (bhur loka, bhuwah loka, dan swah loka). Permukiman dapat "hidup" karena haal ini sehingga diyakini adanya kemampuan untuk melindungi dan membawa kesejahteraan bagi rakyatnya. Kemampuan itu diciptakan oleh eksistensi metafisik (niskala) pada leluhur desa yang sering melakukan interaksi dengan eksistensi fisik (sekala) masyarakat desa melalui penyelenggaraan bermacammacam ritual.

Permukiman desa adat yaitu bhuwana agung (makrokosmos) dan penghuninya yaitu bhuwana alit (mikrokosmos). Ruang memiliki artian komprehensif yang luas, bukan sekadar ruangan mistis berfungsi sebagai suatu komponen dalam kosmologis. Keduanya terdiri dari lima elemen dasar yaitu panca mahabhuta terdiri atas pertiwi (tanah/zat padat), apah (air/zat cair), teje (api/cahaya/panas), bayu (udara/angin), dan akasa (ruang/eter). Dalam tujuan Hindu, yaitu pencapaian kebebasan spiritual, sebagai bhuwana alit, manusia diwajibkan memiliki hubungan baik dengan kosmos yang lebih luas, antara lain rumah tinggalnya, desa, permukiman, bumi, dan akhirnya jagat raya selaku bhuwana agung.

Konsep keseimbangan yang harmonisterdiri dari tataran sekala dan niskala, maupun antarkosmosyang dipercaya sebagai landasan dalam mencapai kemakmuran dan kesejahteraan. Dalam penerapannya, telah dikembangkan menjadi ajaran religius atau tri hita karana atau 'tiga hal penyebab kebaikan' [8][9][10]. Untuk menciptakan ruang bermukim, ajaran ini bertujuan mempererat hubungan harmonis antara manusia dan entitas spiritual Sang Hyang Widhi (Tuhan), dewa-dewa, dan para leluhur, makhluk hidup dengan lingkungan hidupnya, juga antar manusia. Konsep ini dapat dilihat di desa adat di Bali dalam organisisi keruangan.

\section{METODE PENELITIAN}

Pendekatan penelitian kualitatif digunakan untuk mengamati manusia dan bahasa serta istilah yang dipelajari dalam ilmu pengetahuan sosial [11] dan data deskriptif dari ucapan subjek dan perilaku yang diamati akan dihasilkan melalui metode kualitatif [12], serta beberapa hal unik yang ada dalam diri individu, kelompok, masyarakat, ataupun organisasi dapat diungkap secara menyeluruh, rinci, dalam, dan dapat dipertanggungjawabkan secara ilmiah [13].

\section{A. Responden}

Masyarakat Ampel dimanfaatkan peneliti sebagai responden karena mereka yang lebih memahami sejarah lingkungan ataupun bangunan yang ada di Ampel. Peneliti 
juga meminta ahli sejarah yang mengetahui sejarah Ampel dan memiliki bukti fisiknya.

\section{B. Pengumpulan Data}

Peneliti mengakumulasi data-data dengan cara survei primer dan survei sekunder. Survei primer dilakukan dengan cara pengamatan langsung di lapangan dan wawancara. Sedangkan survei sekunder dilakukan dengan survei instansional dan peninjauan literatur.

\section{Tahap Penelitian}

Terdapat tiga langkah yang dilakukan oleh peneliti, yaitu: identifikasi elemen pembentuk citra berdasarkan histori, identifikasi elemen pembentuk citra pada masa sekarang, dan konsep perancangan.

\section{Analisis Data}

Analisis kualitatif merupakan salaah satu jenis analisis yang digunakan oleh peneliti. Analisis ini dilakukan dengan menganalisis elemen pembentuk citra kawasan berserta nilai sejarahnya menggunakan teknik content analysis, dan menganalisis elemen citra kawasan menggunakan perceptual mapping.

\section{HASIL DAN PEMBAHASAN}

\section{A. Citra Kawasan Ampel Abad 16 Masehi}

Pada abad 16 Masehi (16 M), elemen citra yang terbentuk yaitu Islam, Jawa, dan Hindu. Elemen path terbentuk sesuai dengan pendekatan Islam karena Jalan Ampel Masjid menghubungkan Jalan Ampel Suci dengan Sungai Pegirian. Node di kawasan Ampel tercipta sesuai dengan pendekatan Islam karena adanya kegiatan keagamaan di kawasan Ampel, yaitu terdapat di pendopo yang terletak di sekitar area masjid yang digunakan sebagai area untuk melakukan kegiatan keagamaan. Dengan adanya pendopo tersebut, tercipta prinsip hablumminannas dan hablumminallah. Elemen edges terbagi menjadi 2 kawasan yaitu kawasan luar, dengan batas Sungai Pegirian karena dermaga sungai pegirian berada tepat didepan Jalan Ampel Masjid sehingga masyarakat keluar dan masuk akan memahami jika berada dalam kawasan Ampel, dan batas bagian dalam kawasan dibatasi oleh 5 gapura dengan pendekatan Hindu yang merupakan peninggalan Kerajaan Majapahit sekaligus sebagai batas sakral dan profane pada kawasan. Elemen selanjutnya adalah district dan yang identik adalah kawasan permukiman masyarakat yang terbentuk karena Raden Rahmat membawa ribuan keluarga menuju kawasan Ampel dan akhirnya menciptakan sebuah kawasan permukiman yang masih belum tertata secara rapi. Tetapi, permukiman berorientasi dengan posisi Masjid, yaitu arah kiblat, sehingga dengan pendekatan Islam. Kemudian, elemen terakhir yaitu landmark yang sangat khas sekali dengan keberadaan Masjid Ampel. Tujuan datangnya Raden Rahmat menuju kawasan Ampel memang dalam misi mengembangkan ajaran agama Islam, sehingga sesampainya Raden Rahmat di Ampel langsung membangun Masjid Ampel dan dengan keberadaan masjid ini sebagai pendekatan Islam.

Tabel 1.

Hasil Elemen Pembentuk Abad 16 M

\begin{tabular}{|c|c|c|c|c|c|}
\hline \multirow{2}{*}{ No. } & \multirow{2}{*}{$\begin{array}{l}\text { Elemen } \\
\text { Citra }\end{array}$} & \multirow{2}{*}{ Penjelasan } & \multicolumn{3}{|c|}{ Approach } \\
\hline & & & Islam & Jawa & Hindu \\
\hline 1. & Path & $\begin{array}{l}\text { Jalan Ampel } \\
\text { Masjid sebagai } \\
\text { jalur utama } \\
\text { kegiatan Kawasan } \\
\text { Ampel dan Jalan } \\
\text { Ampel Suci } \\
\text { sebagai jalan jalur } \\
\text { aktifitas } \\
\text { permukiman. }\end{array}$ & - & - & - \\
\hline 2. & Node & $\begin{array}{l}\text { Yang digunakan } \\
\text { masyarakat untuk } \\
\text { melakukan } \\
\text { kegiatan } \\
\text { berkumpul sejenak } \\
\text { yaitu area pendopo } \\
\text { yang terdapat di } \\
\text { sekitar masjid. }\end{array}$ & - & - & - \\
\hline & & $\begin{array}{l}\text { Bagian dalam } \\
\text { kawasan dibatasi } \\
\text { oleh } 5 \text { gapura. }\end{array}$ & & & $\mathrm{v}$ \\
\hline 3. & Edge & $\begin{array}{l}\text { Bagian luar } \\
\text { kawasan dibatasi } \\
\text { oleh Sungai } \\
\text { Pegirian. }\end{array}$ & - & - & - \\
\hline 4. & District & $\begin{array}{l}\text { Seluruh } \\
\text { permukiman } \\
\text { berorientasi dan } \\
\text { berpusat kepada } \\
\text { Masjid Ampel. }\end{array}$ & $\mathrm{v}$ & & \\
\hline 5. & Landmark & $\begin{array}{l}\text { Berfungsi sebagai } \\
\text { pusat bagi seluruh } \\
\text { Kawasan Ampel } \\
\text { dan memiliki } \\
\text { arsitektural atap } \\
\text { Tajug bersusun } 3 \text {, } \\
\text { bermahkota emas, } \\
\text { dan memiliki } 4 \\
\text { sokoguru yang } \\
\text { menopang atap } \\
\text { Tajug. }\end{array}$ & $\mathrm{v}$ & $\mathrm{v}$ & \\
\hline
\end{tabular}

\section{B. Citra Kawasan Ampel Abad 16 M-Sekarang}

Pada masa sekarang, elemen citra yang terbentuk yaitu sesuai dengan pendekatan Islam, Jawa, dan Hindu. Namun, pada masa sekarang pendekatan yang lebih kompleks atau yang secara tangible yaitu pendekatan berdasarkan Islam. Karena komponen yang terdapat pada masa sekarang sangat kompleks berdasarkan dengan pendekatan Islam. Sirkulasi jalan atau path yang tercipta pada masa sekarang yaitu pola jalan grid-linier. Perpaduan yang dihasilkan tersebut membuat ciri khas tersendiri untuk pemukiman Islam yang ada dan telah menjadi icon untuk Kawasan Ampel. Dapat dilihat bahwa bentuk sirkulasi jaringan jalan pada Kawasan Ampel memiliki sahri yaitu jalan utama, fina yaitu jalan kecil dan juga cul-desac yaitu jalan buntu. Masyarakat sering melakukan pemberhentian sementara pada kawasan Ampel yaitu pada area ruang terbuka sekitar makam, sehingga area tersebut sering dijadikan sebagai node bagi para pengunjung dan 
dengan adanya node tersebut dapat menciptakan hablumminannas antar pengunjung yaitu nilai ukhuwah yaitu interaksi sosial. Yang menjadi edge atau batas kawasan Ampel yaitu berupa suqs atau distrik perdagangan dan jasa dimana district ini merupakan penggerak perkonomian kawasan tersebut dan kriteria tersebut identik dengan kawasan Islam dan suqs tersebut jika diamati bahwa strukturnya mengelilingi area inti kawasan Ampel, sehingga posisi masjid sebagai center terdapat pada bagian dalam kawasan. Sehingga, dapat diartikan sebagai dinding kota dan selain dinding kota juga terdapat gate masuk berupa gapura yang dapat diartikan bahwa gapura tersebut merupakan area pintu masuk menuju area inti kawasan. District pada kawasan Ampel terdapat 3 district yaitu district permukiman, district perdagangan dan jasa atau suqs, dan district ibadah yang terletak di sepanjang jalan Ampel Masjid dan Ampel Suci. Ketiga district tersebut sangat identik dengan karakteristik kawasan Islam karena district ibadah dan perdagangan dan jasa menjual seluruh kebutuhan ibadah keagamaan dan kemudian district permukiman sangat memperhatikan sekali aspek privasi yang tercipta dalam Islam dan yang unik yaitu beberapa permukiman masih memiliki keaslian arsitektur dengan pengaruh arsitektur Jawa. Elemen pembentuk landmark yaitu keberadaan Masjid Ampel. Keberadaan Masjid Ampel menjadi poros atau pusat segala kegiatan yang ada di kawasan Ampel, termasuk dengan pengaturan arah hadap rumah yang sangat dipengaruhi dengan adanya keberadaan Masjid Ampel karena seluruh permukiman di kawasan Ampel menggunakan hadap timur-barat atau arah kiblat menghadap Masjid Ampel. Selain masjid digunakan sebagai pusat atau poros pada kawasan Ampel, Masjid Ampel juga memiliki ciri khas arsitektur pada bangunannya yaitu bergaya arsitektural Jawa. Masjid Ampel hingga kini masih bertahan dengan ciri khas arsitektural budaya Jawa. Masjid lama ini masih menggunakan tipe Demakan, di mana bangunannya berbentuk bujursangkar yang di dalamnya terdapat empat sokoguru yang dibuat dari kayu jati sebagai penyangga atap Tajug bersusun dua. Bangunan ini sebagai bangunan induk yang memiliki menara dengan puncak mengerucut. Bagian terluas dari masjid ini ada pada sisi utara. Sedangkan di sisi sebelah barat dibangun masjid yang baru. Di bagian terluas masjid dapat dilihat gaya khas yang dipadu padankan antara lain atap Tajug dengan unsur gaya modern dan Pan Islamic, yag berstruktur geometri dan arabesk. Atap masjid baru ini memiliki gaya ciri khasnya yang berpadu dengan gaya modern, hal ini dapat dilihat dari atap Tajug yang membentuk rusuk-rusuk di bagian atasnya serta terdapat kubah di dalamnya (Santoso, 1999).

Tabel 2.

Hasil Elemen Pembentuk Abad 16 M - Sekarang

\begin{tabular}{|c|c|c|c|c|c|}
\hline \multirow{2}{*}{ No. } & \multirow{2}{*}{$\begin{array}{c}\text { Elemen } \\
\text { Citra }\end{array}$} & \multirow{2}{*}{ Penjelasan } & \multicolumn{3}{|c|}{ Approach } \\
\hline & & & Islam & Jawa & Hindu \\
\hline 1. & Path & $\begin{array}{l}\text { Kawasan Ampel } \\
\text { memiliki } \\
\text { perpaduan pola } \\
\text { sirkulasi grid- } \\
\text { linier yang } \\
\text { menciptakan } \\
\text { jalan utama } \\
\text { (shari) yang }\end{array}$ & $\mathrm{v}$ & & \\
\hline
\end{tabular}

\begin{tabular}{|c|c|c|c|c|c|}
\hline & & $\begin{array}{l}\text { dihubungkan } \\
\text { secara lurus dan } \\
\text { paralel oleh } \\
\text { jalan-jalan kecil } \\
\text { (fina) yang } \\
\text { membujur dari } \\
\text { arah timur-barat } \\
\text { dan kemudian } \\
\text { tercipta sebuah } \\
\text { jalan buntu (cul- } \\
\text { de-sac). }\end{array}$ & & & \\
\hline 2. & Node & $\begin{array}{l}\text { Area yang sering } \\
\text { digunakan oleh } \\
\text { masyarakat } \\
\text { untuk berhenti } \\
\text { sejenak yaitu } \\
\text { terdapat pada } \\
\text { ruang terbuka } \\
\text { sekitar makam } \\
\text { Sunan Ampel. }\end{array}$ & $\mathrm{v}$ & & \\
\hline & & $\begin{array}{l}\text { Batas dalam } \\
\text { kawasan yaitu } \\
\text { dibatasi oleh } 5 \\
\text { gapura. }\end{array}$ & & & $\mathrm{v}$ \\
\hline 3. & Edge & $\begin{array}{l}\text { Batas luar } \\
\text { kawasan yaitu } \\
\text { suqs atau } \\
\text { perdagangan dan } \\
\text { jasa serta } \\
\text { terdapat gerbang } \\
\text { berupa gapura. }\end{array}$ & $\mathrm{v}$ & & \\
\hline 4. & District & $\begin{array}{l}\text { Terdapat } 3 \\
\text { district yaitu } \\
\text { district } \\
\text { permukiman, } \\
\text { district ibadah, } \\
\text { dan district suqs. }\end{array}$ & $\mathrm{v}$ & $\mathrm{v}$ & \\
\hline 5. & Landmark & $\begin{array}{l}\text { Berfungsi } \\
\text { sebagai pusat } \\
\text { bagi seluruh } \\
\text { kawasan Ampel } \\
\text { dan memiliki } \\
\text { arsitektural atap } \\
\text { Tajug bersusun } \\
\text { 3, bermahkota } \\
\text { emas, dan } \\
\text { memiliki } 4 \\
\text { sokoguru yang } \\
\text { menopang atap } \\
\text { Tajug. }\end{array}$ & $\mathrm{v}$ & $\mathrm{v}$ & \\
\hline
\end{tabular}

\section{Arahan dan Strategi Pengembangan Kawasan Ampel}

\section{Path (jalur)}

Pengembangan vegetasi berupa penghijauan guna mengembangkan keterikatan antara manusia dan Tuhan melalui prinsip konsep habluminallah.

- Pengembangan vegetasi penghijauan pada area shari guna meningkatkan teduhan bagi para pengunjung.

- Pengembangan vegetasi penghijauan berupa area taman kecil pada area fina guna meningkatkan batas (harm) hak seseorang terhadap orang lain 
dan meningkatkan aspek privasi antara jalan sebagai area publik dan permukiman masyarakat sebagai area privasi

\section{Node (simpul)}

Perlu adanya pengembangan terhadap area ruang terbuka yang terdapat di sekitar area makam utama karena area tersebut sering sekali digunakan oleh pengunjung sebagai area untuk menunggu sanak saudara.

3. Edge (batas)

Pengembangan fasad 'muka bangunan' pada deretan bangunan perdagangan dan jasa dengan menggunakan material bahan yang menyatu dengan alam seperti material berbahan batu atau kayu dengan sentuhan warna cokelat yang selaras dengan prinsip konsep habluminallah. Perlu adanya sentuhan pengembangan visual sesuai dengan visual karakter Islam pada bangunan dengan menerapkan Prinsip Tampilan Visual Islam seperti Arabesque, Kaligrafi, Mashrabiya, dan Lengkung Tapal Kuda. Batas berupa perdagangan dan jasa didukung dengan adanya keberadaan jalur pedestrian yang juga dibutuhkan arahan berupa pengembangan vegetasi penghijauan sebagai media teduhan bagi para pejalan kaki serta mempererat ikatan yang terjalin antara manusia dan Tuhannya dengan prinsip habluminallah dan dengan adanya vegetasi berupa penghijauan seperti pohon dapat memberi batas (harm) hak milik antara pejalan kaki dengan jalur kendaraan. Mempertahankan bentuk dari gapura pintu masuk dan 5 gapura dengan melakukan preservasi berupa pengecatan ulang.

\section{District (kawasan)}

- Pengembangan district permukiman dalam bentuk perumahan kampung dengan karakter khas langgam nusantara dan pengembangan fasad muka bangunan dengan menggunakan material bahan yang menyatu dengan alam seperti material berbahan batu atau kayu dengan sentuhan warna cokelat yang selaras dengan prinsip konsep habluminallah dengan sedikit sentuhan yang sesuai dengan Prinsip Tampilan Visual Islam seperti Arabesque, Kaligrafi, Mashrabiya, dan Lengkung Tapal Kuda. Perlu adanya pengembangan vegetasi penghijauan berupa taman sederhana depan rumah guna meningkatkan teduhan bagi para pengunjung serta memupuk kedekatan manusia dengan Tuhan melalui konsep habluminallah.

- Pada district ibadah dan perdagangan dan jasa, perlu adanya pengembangan fasad muka bangunan pada deretan bangunan district ibadah dan district perdagangan dan jasa dengan menggunakan material bahan yang menyatu dengan alam seperti material berbahan batu atau kayu dengan sentuhan warna cokelat yang selaras dengan prinsip konsep habluminallah serta pengembangan vegetasi penghijauan berupa pohon guna meningkatkan filter cuaca dan media teduhan serta mempererat ikatan manusia dengan Tuhan sesuai dengan prinsip konsep habluminallah.

\section{Landmark (tengara)}

Melakukan preservasi pada bangunan Masjid Ampel guna mempertahankan keaslian bangunan. Masjid Ampel merupakan bagunan dengan Tipe A yang merupakan bangunan yang tidak boleh dirubah bentuk bangunannya, sehingga perlu dilakukan preservasi pada bangunan Masjid Ampel.

\section{KESIMPULAN DAN SARAN}

Ada beberapa yang dapat kita ambil dari penelitian ini yaitu pendekatan Islam, Jawa, dan Hindu yang terdapat pada 5 komponen pembentuk citra kawasan masih belum terbentuk secara utuh pada masing-masing komponennya. Dengan seiring berjalannya waktu, jika dilihat perkembangan Kawasan Ampel pada saat ini sangat terlihat dengan jelas bahwa 5 komponen pembentuk citra kawasan mengarah pada pendekatan Islam yang sangat kompleks dan pendekatan ini dipengaruhi oleh awal mula berdirinya Masjid Ampel yang berfungsi sebagai poros perkembangan Islam di Kawasan Ampel. Maka dari itu, hasil temuan penelitian ini dapat dijadikan sebagai acuan dalam mengembangkan Kawasan Ampel agar sesuai dengan komponen citra yang berkembang dan pada akhirnya Kawasan Ampel memiliki value sesuai dengan citra yang berkembang pada Kawasan Ampel.

\section{DAFTAR PUSTAKA}

[1] Vica Yulintania, Ir. T. Yoyok Wahyu Subroto, M.Eng., Ph.D. ( 2013) PENATAAN RUANG JALAN DI KAWASAN AMPEL DENGAN KONSEP LIVABLE STREET (studi kasus : koridor Jalan Nyamplungan dan Pegirian, Surabaya)

[2] Badan Perrencanaan Pembangunan Kota Surabaya (2019). Ringkasan Eksekutif Review Penataan Kawasan Ampel Surabaya

[3] Kevin Lynch, 1982. A Theory of Good City Form. The MIT Press; First Edition edition (March 3, 1981). ISBN-10: 0262120852. ISBN13: 978-0262120852

[4] Kevin Lynch, 1972. What Time Is This Place?. The MIT Press (October 15, 1976). ISBN-10: 0262620324. ISBN-13: 9780262620321

[5] Kevin Lynch, 1960. The Image of The City. The MIT Press (June 15, 1960). ISBN-10: 0262620014. ISBN-13: 978-0262620017

[6] Nuraini (2011). KAJIAN PELESTARIAN KAMPUNG KAUMAN KUDUS SEBAGAI KAWASAN BERSEJARAH PENYEBARAN AGAMA ISLAM. Jurusan Teknik PWK Fakultas Teknik Universitas Diponegoro. TEKNIK - Vol. 32 No. 1 Tahun 2011, ISSN 0852-1697.

[7] Kusumastuti (Januari, 2016). PROSES DAN BENTUK "MEWUJUDNYA" KOTA SOLO BERDASARKAN TEORI CITY SHAPED SPIRO KOSTOF. PROGRAM STUDI PERENCANAAN WILAYAH DAN KOTA FAKULTAS TEKNIK UNIVERSITAS SEBELAS MARET, SURAKARTA. Region, Vol. 1, No. 1, Januari 2016: $1-51$.

[8] I Gusti Ketut Kaler, 1983. Butir - Butir Tercecer Tentang Adat Bali, Volume 1. Bali Agung, 1983. the University of Michigan. 20 Aug 2007.

[9] Surpha, W., 1991. Eksisten si Desa Adat di Bali (The Existence of Desa Adat in Bali). Den pasar: Upada Sastra

[10]I Gde Pitana, I Ketut Nehen, 1994. Dinamika Masyarakat dan Kebudayaan Bali: Sebuah Antologi. the University of Michigan. 24 Sep 2009. ISBN- 979849606X, 9789798496066.

[11]Kirk, J., \& Miller, M. L. (1986). Qualitative Research Methods: Reliability and validity in qualitative research. Newbury Park, CA: SAGE Publications, Inc. doi: 10.4135/9781412985659

[12]Bogdan dan Taylor, 1975 dalam J. Moleong, Lexy. 1989. Metodologi Penelitian Kualitatif. Bandung: Remadja Karya 
[13] Miles, Mathew B., dan A. Michael Huberman. 1994. An Expanded Sourcebook: Qualitative Data Analysis. London: Sage Publications.

[14] Tuan, Yi-Fu (1977). Space and Place: The Perspective of Experience. Minneapolis: University of Minnesota Press

[15] Tjandrasasmita, U. (2009). Arkeologi Islam Nusantara. Jakarta : Kepustakaan Populer Gramedia (KPG).

[16] Anonim. (2010). Undang Undang No.11 Tahun 2010 Tentang Cagar Budaya. Pemerintah Republik Indonesia.

[17] Bathuthah, M. B. (2012). Rihlah Ibnu Batutah: Memoar Perjalanan Keliling Dunia di Abad Pertengahan. Jakarta :Pustaka Al-Kautsar.

[18] Handoko, W. (2013). Arsitektur Masjid Kuno dan Perkembangan Islam di Maluku. Jurnal Penelitian dan Pengembangan Arkeologi: Jakarta: Pusat Penelitian Arkeologi Nasional.

[19] Tjandrasasmita, U. (2009). Arkeologi Islam Nusantara. Jakarta : Kepustakaan Populer Gramedia (KPG).

[20] Suwoto. (2009). Folklor Menara, Masjid, Dan Makam Sunan Kudus Sebagai Pengayaan Materi Pembelajaran Sejarah (Studi Kasus Di Madrasah Aliyah Nahdlatul Ulama Banat Kudus). Thesis. Solo : Universitas Sebelas Maret.

[21] UNESCO (2017). List of World Heritage. Retrieve from http://whc.unesco.org/en/list/ . Pada Tanggal 4 Juli 2018 Pukul

[22] Favory, F., Nuninger, L. \& Sanders, L. (2012). Intégration de concepts de géographie et d'archéologie spatiale pour l'étude des systèmes de peuplement. L'Espace géographique, vol. 41,(4), 295309. https://www.cairn.info/revue-espace-geographique-2012-4page-295.htm

[23] Susan M. Walcott (2006) Mapping from a Different Direction: Mandala as Sacred Spatial Visualization, Journal of Cultural Geography, 23:2, 71-88, DOI: 10.1080/08873630609478223

[24] Azra, Azumardi (2013). Jaringan Ulama' Timur Tengah dan Kepulauan Nusantara Abad XVII \& XVII. Jakarta, Penerbit Kencana.

[25] Holm, J., \& Bowker, J. (2001). Sacred Place. Bloomsbury Publishing.

[26] Jochim, M. A. (1991). Archeology as Long-Term Ethnography. American Anthropologist, 93(2).

[27] Kennedy, R., \& Widjojoatmodjo, A. K. (1943). Acculturation and administration in Indonesia. American Anthropologist, 45(2), 185192

[28] Lefebvre, Henry. (1991). The Production of Space. Malden, MA: Blackwell. Original work published in 1974.

[29] Pradisa, Andanti Puspita Sari. (2017). Perpaduan Budaya Islam dan Hindu dalam Masjid Menara Kudus. SAPPK ITB. Raynaud C. (2007). Archéologie d'un village languedocien. Lunel-Viel (Hérault) du Ier au XVIIIe siècle. Lattes: Publications de l'Umr 5140 du Cnrs, Édition de l'Association pour le développement de l'archéologie en Languedoc-Roussillon, coll. "Monographies d'archéologie méditerranéenne", 407 p 